\title{
Grenzen aan de autonomie van strafrechters: wie bewijst de stoornis en het recidiverisico?
}

\author{
A.R. Mackor ${ }^{*}$
}

\section{Inleiding}

Rechters worden bij uitstek gekarakteriseerd als autonome professionals. Autonomie wordt hier bedoeld in de kantiaanse zin dat een professional zichzelf als redelijk en zedelijk wezen de wet kan stellen, daarnaar kan handelen en daarover (desgevraagd) verantwoording kan afleggen. ${ }^{1}$ Weliswaar kadert de wetgever - die de rechter letterlijk de wet stelt - de professionele autonomie van de rechter in, maar binnen deze grenzen is de rechter autonoom in de uitoefening van zijn professie. De rechter is autonoom in de wijze waarop hij algemene normen interpreteert en feiten kwalificeert om zo tot een beslissing in een concrete zaak te komen. De rechter is bovendien bij uitstek een professional die verantwoording aflegt. Dit doet hij in de rechterlijke motivering.

Dit alles geldt uiteraard ook voor de strafrechter. Deze is aan de wet gebonden, maar heeft in concrete gevallen meer of minder interpretatievrijheid. Dit geldt zowel ten aanzien van de uitleg van de regels (en daarmee ook ten aanzien van de toepasselijkheid van regels) als ten aanzien van de vaststelling en de uitleg (en daarmee ten aanzien van de relevantie) van de feiten.

Anne Ruth Mackor is filosoof en jurist. Zij is als hoogleraar professie-ethiek, in het bijzonder van juridische professies aan de Faculteit Rechtsgeleerdheid en als Socrates hoogleraar professionele ethiek aan de Faculteiten Godgeleerdheid \& Godsdienstwetenschap en Wijsbegeerte verbonden aan de Rijksuniversiteit Groningen.

1 A.R. Mackor, Grenzen aan professionele autonomie, in Themanummer Professionele Autonomie, Rechtsgeleerd Magazijn Themis 172 (2011) 4, pp 143-150. 
Vooral waar het de vaststelling en de uitleg van de feiten betreft, komt de strafrechter opmerkelijk veel autonomie toe. Het strafrechtelijke bewijsrecht is namelijk wel uitvoerig en gedetailleerd als het de rechtmatigheid van het bewijs betreft, maar waar het om de betrouwbaarheid van het bewijs gaat, is het uiterst summier. Het Nederlandse strafrechtelijke bewijsrecht heet een negatief (artikel 338 Sv) wettelijk (artikel 339 Sv) stelsel te zijn, maar velen hebben beweerd dat het feitelijk een vrij stelsel is. ${ }^{2}$

Dat wordt niet in de laatste plaats geweten aan het feit dat de Hoge Raad de toch al summiere wetgeving op het terrein van het bewijsrecht heeft uitgehold, onder meer door het de auditu-arrest en de uitleg van de regel unus testis nullus testis. ${ }^{3}$ Daar komt bij dat de strafrechter in beginsel vrij is in de selectie en waardering van het bewijsmateriaal en bovendien tot voor kort ten aanzien van bewijsverweren slechts een zeer beperkte motiveringsplicht had. Ondermeer Dreissen en Knigge betogen dan ook, dat daardoor nauwelijks een bewijsleer is ontwikkeld. ${ }^{4}$ De motiveringsplicht is in 2005 aangescherpt door artikel 359 lid $2 \mathrm{~Sv}$, waarin is voorgeschreven dat de rechter een uitdrukkelijk onderbouwd standpunt van Openbaar Ministerie (OM) of verdediging gemotiveerd moet weerleggen. Voor die tijd kon de rechter ongemotiveerd voorbij gaan aan een dergelijk standpunt. De Hoge Raad stelt bovendien tegenwoordig, althans op het eerste gezicht, strengere eisen aan

2 Het is een wettelijk stelsel omdat de rechter gebonden is aan in de wet genoemde bewijsmiddelen, het is negatief omdat hij niet tot bewezenverklaring mag komen als hij niet overtuigd is geraakt van het feit dat de verdachte het tenlastegelegde feit heeft begaan. Een vrij stelsel houdt in dat de rechter niet aan regels is gebonden, maar geheel vrij is in zijn keuze en waardering van bewijsmiddelen. Aangezien de wet de rechter nauwelijks beperkingen oplegt is het stelsel de facto vrij te noemen.

3 In het de auditu-arrest heeft de Hoge Raad verklaard dat de rechter zijn oordeel mag baseren op wat een getuige van iemand anders heeft gehoord (de auditu). Dit gaat met name in tegen de eis van eigen waarneming (artt. 342 lid 1 en 344 lid 1 sub $2 \mathrm{~Sv}$ ). De unus testis nullus testis regel (een getuige is geen getuige) wordt beperkt uitgelegd. De bewezenverklaring van de tenlastelegging als geheel mag niet op een getuigenverklaring worden gebaseerd, maar belangrijke onderdelen van de tenlastelegging mogen in beginsel wel op die grond bewezen worden verklaard.

4 W.H.B. Dreissen, Bewijsmotivering in strafzaken, Den Haag: Boom Juridische uitgevers, 2007; G. Knigge, Redactioneel. Niet uitleggen maar verantwoorden, Rechtsgeleerd Magazijn Themis 169 (2008) 6, pp 233-234 en G. Knigge in zijn conclusie bij HR 2 februari 2010, LJN: BJ7266. 
de verwerping van het bewijsverweer dat de belastende getuigenverklaring geheel op zichzelf staat (een schending van de regel unus testis nullus testis). Deze veranderingen hebben echter zeker nog niet tot ontwikkeling van een bewijsleer geleid. Zo spreekt Borgers (in een noot bij HR 13 juli 2010, LJN BM2452, onder punt 4) over 'het casuïstische karakter van de rechtspraak van de Hoge Raad'.

\section{Autonomie en deskundigheid}

Het mag op zijn minst opmerkelijk heten dat aan de rechter, uitgerekend op het terrein waarop hij het minst deskundig is: vaststelling van de betrouwbaarheid van bewijs, de meeste vrijheid toekomt. Ik spreek hier bewust over vrijheid in plaats van autonomie, omdat we ons kunnen afvragen of de rechter zich op dit punt wel als redelijk wezen kán gedragen, of hij zichzelf op dit punt wel de wet kán stellen en of hij zich op dit punt wel kán verantwoorden. ${ }^{5}$ De vraag is dan ook of rechters op dit belangrijke punt op hun overtuiging moeten afgaan (artikel $338 \mathrm{~Sv}$ ). Mogen of misschien zelfs moeten zij eigen betrouwbaarheidsregels maken? Of moeten zij vooral op het oordeel van deskundigen afgaan en zich conformeren aan de wetenschappelijke theorieën en de richtlijnen voor betrouwbaar bewijs die deskundigen zichzelf op dit punt opleggen? ${ }^{6}$

Naar aanleiding van enkele geruchtmakende rechterlijke dwalingen is de discussie tussen juristen en deskundigen, maar ook tussen juristen onderling in een aantal gevallen hoog opgelopen. ${ }^{7}$ De kritiek van deskundigen richt

5 A.R. Mackor, Grenzen aan professionele autonomie, in Themanummer Professionele Autonomie, Rechtsgeleerd Magazijn Themis 172 (2011) 4, pp 143-150 en A.R. Mackor Nederlandse strafrechters hebben te veel autonomie, Opinie op de RuG-site, 24.1.2011, http://www.rug.nl/corporate/nieuws/opinie/2011/opinie5_2011.

6 Daarbij rijst overigens de vraag wie deskundigen zijn. Deze kwestie stelt zich des te indringender nu deskundigen het onderling lang niet altijd eens zijn. Deskundigen zijn het niet altijd eens op het niveau van de theorie. Zelfs wanneer zij het daarover wel eens zijn, dan kunnen ze ook nog van mening verschillen over de concrete casus.

7 Vergelijk bijvoorbeeld de discussie tussen Wagenaar et al. W.A. Wagenaar, H. Israëls en P.J. van Koppen, De slapende rechter. Waarom het veroordelen van burgers niet alleen aan de rechter kan worden overgelaten, Amsterdam: Uitgeverij Bert Bakker, 2009 en 
zich ondermeer op het te grote belang dat wordt toegekend aan de rechterlijke overtuiging. Daarnaast luidt de kritiek dat sommige juristen allerlei verschillen tussen rechterlijke en wetenschappelijke methoden van bewijsvinding poneren die bij nader inzien geen stand houden. Juristen brengen daartegenin dat deskundigen te weinig begrijpen van het eigene van bewijs en waarheidsvinding in de strafrechtspraak en dat bewijs in de strafrechtspraak wezenlijk anders is dan in de wetenschap. ${ }^{8}$

Deze discussie is vooral gevoerd over de bewezenverklaring van het strafbare feit, maar de vraag dringt zich op of deze discussie niet evenzeer zou moeten worden gevoerd in het kader van de oplegging en verlenging van de terbeschikkingstelling (tbs). Deze vraag stel ik het vervolg van mijn betoog centraal. Hierbij moet worden opgemerkt dat de zojuist genoemde regels met betrekking tot de bewijsmotivering (artikelen $338 \mathrm{~Sv}$ e.v.) alleen betrekking hebben op de eerste materiële vraag van artikel 350 Sv: de vraag naar de bewezenverklaring van het tenlastegelegde feit. Zij zijn niet van toepassing op de tweede vraag (de kwalificatie van het feit) en evenmin op de derde (is de dader strafbaar?) en vierde materiële vraag (welke straf?) die in deze bijdrage centraal staan. Mijn stelling is dat de discussie over de betrouwbaarheid van het strafrechtelijke bewijs evenzeer gevoerd moet worden over de vaststelling van stoornis en recidiverisico. Een jurist zou echter bezwaar kunnen maken tegen het gebruik van de termen bewijs en bewezenverklaring in deze context. Ik zal beide termen daarom steeds tussen aanhalingstekens plaatsen wanneer ik spreek over de vaststelling van stoornis en recidiverisico.

W.A. Wagenaar, P.J. van Koppen en H. Israëls, 'Een niet erg wakkere raadsheer,' Nederlands Juristenblad 84 (2009) 23 en M.A. Loth, "Slapende rechters' of 'dwalende deskundigen', Nederlands Juristenblad 84 (2009) 18, pp 1142-1147 en M.A. Loth, 'Slapende rechters' of 'dwalende deskundigen'. Naschrift', Nederlands Juristenblad 84 (2009) 23, p 1451 alsmede verschillende bijdragen in het themanummer van Rechtsgeleerd Magazijn Themis 171 (2010) 6, over rechterlijke waarheidsvinding.

8 A.R. Mackor, 'Wat is waarheid?' De rol van deskundigen bij waarheidsvinding in de strafrechtspraak, Rechtsfilosofie \& Rechtstheorie 39 (2010) 1, pp 52-66 en A.R. Mackor, Aard en belang van waarheid in het strafproces, Bart Krans et al. (red), Deskundige in het recht, Zutphen: Uitgeverij Paris, 2011, pp 157-173. 


\section{Betrouwbaar oordeel over gevaar en stoornis}

De binnen het bestek van artikel $37 \mathrm{Sr}$ te beantwoorden vraag of het strafbare feit aan de verdachte kan worden toegerekend draagt grotendeels een normatief karakter en is daardoor een specifiek juridische vraag. Voor de vraag of tbs moet worden opgelegd, geldt dat al minder, omdat daarvoor onder meer vereist is dat de veiligheid van anderen dan wel de algemene veiligheid de oplegging van die maatregel eist (artikel 37a, lid 1, sub $2 \mathrm{Sr}$ ). Uiteraard kent de vraag of de hier bedoelde veiligheid het opleggen van de maatregel vereist wel juridische aspecten, maar de vraag of verdachte een gevaar vormt voor personen, goederen of de algemene veiligheid, is grotendeels een feitelijke kwestie. Dit geldt ook voor een andere vraag die moet worden beantwoord voordat tbs kan worden opgelegd, te weten de vraag of bij de dader tijdens het begaan van het strafbare feit een gebrekkige ontwikkeling of ziekelijke stoornis van zijn geestvermogens bestond. De vaststelling van een dergelijke stoornis is vereist voor het opleggen van tbs (artikel 37a lid 1; zie ook HR, 9 januari 2001, LJN AD 4678).

De wetgever lijkt van oordeel te zijn dat de vaststelling van een stoornis een feitelijke kwestie is die een specifieke deskundigheid vereist. Artikelen 37a lid 3 en 37 lid 2 Sr eisen immers dat de rechter zich door tenminste twee gedragsdeskundigen, waaronder een psychiater, heeft laten adviseren voordat hij tbs oplegt. In dit advies dienen de gedragsdeskundigen ondermeer een oordeel te geven over de vraag of er sprake was van een gebrekkige ontwikkeling of ziekelijke stoornis ten tijde van het begaan van het feit.

Deze eis vervalt echter als de verdachte weigert mee te werken (artikelen 37a lid 3 en 37 lid $3 \mathrm{Sr}$ ). Daarmee wordt niet alleen de - deels normatieve beslissing over het opleggen van tbs geheel in handen van de rechter gelegd, maar ook het - grotendeels feitelijke - oordeel over de aanwezigheid van een stoornis. Dat dit de bedoeling van de wetgever was, staat buiten kijf. De Minister schrijft in de Memorie van Antwoord (MvA) bij de zogeheten

9 Overigens is het opmerkelijk dat voor het opleggen van tbs alleen gelijktijdigheid en geen verband tussen stoornis en strafbaar feit vereist is. Dit discussiepunt laat ik verder echter buiten beschouwing. 
Reparatiewet uit 1994 die een oplossing beoogde te bieden voor 'het probleem' van de weigerende verdachte:

'De beslissing van de rechter over de oplegging van de tbsmaatregel is ... in alle gevallen het resultaat van zijn eigen oordeelsvorming, en dat geldt eveneens voor de vraag of hij daartoe over toereikende gegevens beschikt.' (mijn cursivering, ARM) (Kamerstukken II, 22909, 6, p 3 (MvA)).

Deze vrijbrief aan de rechter staat in scherp contrast met de bewering dat:

'... het doel van het wetsvoorstel is ... een verbetering van de besluitvorming bij het opleggen van de tbs ...' (mijn cursivering, ARM) (Kamerstukken II, 22909, 6, p 1 (MvA)).

De vraag is immers hoe de rechter over 'toereikende gegevens' kan beschíkken en hoe hij kan wéten dat hij daarover beschikt, als er geen gedragsdeskundige adviezen zijn. Nu eist artikel 37a lid $4 \mathrm{Sr}$ weliswaar dat de rechter de inhoud van de overige adviezen en rapporten over de persoonlijkheid van de verdachte in aanmerking neemt, maar artikelen 37a lid 4 en 37 lid $2 \mathrm{Sr}$ eisen niet dat de deskundigen hebben vastgesteld dat de verdachte aan een gebrekkige ontwikkeling of ziekelijke stoornis lijdt.

Opmerkelijk genoeg zien niet alle gedragsdeskundigen hierin een probleem. Mooij betoogt dat het begrip stoornis niet strikt medisch hoeft te worden uitgelegd, omdat het begrip psychische stoornis een conventionele achtergrond heeft. ${ }^{10}$ De vraag rijst echter hoe de rechter een stoornis kan vaststellen als de deskundigen stellen dat zij daarover geen uitspraak kunnen doen. Zelfs als we meegaan in de opvatting dat 'stoornis' een normatief begrip is, dan geldt dat niet voor het risico dat verdachte weer een ernstig strafbaar feit zal plegen. Uiteraard is de vraag welk risico aanvaardbaar wordt geacht een normatieve vraag, maar de bepaling van het risico is zelf geen normatief

10 A.W.M. Mooij, De vraag naar de toerekeningsvatbaarheid, Ontmoetingen, voordrachtenreeks van het Lutje Psychiatrisch-Juridisch Gezelschap, nr 11, 2005, pp 720 , op $\mathrm{p} 12$. 
oordeel. Het is een feitelijke bewering die op basis van empirische en statistische theorieën zou moeten worden gemaakt. De vraag rijst dus nog indringender hoe de rechter daarover kan oordelen. Dit brengt ons bij de Hoogerheide zaak. ${ }^{11}$

\section{De Hoogerheide zaak}

De Hoogerheide zaak, waarin Juliën C. terecht staat op verdenking van moord of doodslag op een achtjarige leerling van een basisschool in Hoogerheide, ligt op dit moment voor de tweede keer bij de Hoge Raad. De laatste uitspraak in deze zaak is van het Gerechtshof Arnhem van 18 mei 2011 (LJN BQ4981). Dit arrest is voor ons van belang, omdat het Hof, net als eerder de Rechtbank Breda op 6 september 2007 (LJN BB3032), maar anders dan het Gerechtshof 's Hertogenbosch op 26 februari 2008 (LJN BC5105), oordeelt dat het zelf heeft kunnen vaststellen dat voldoende aannemelijk is geworden dat bij verdachte ten tijde van het delict een psychische stoornis bestond. Dit is opmerkelijk, omdat de gedragsdeskundigen hebben verklaard dat zij niet in staat waren tot deze vaststelling te komen. Het Hof 's Hertogenbosch veroordeelde Juliën C. voor moord tot levenslange gevangenisstraf. De Rechtbank Breda en ook het Hof Arnhem achtten moord niet bewezen en veroordeelden hem voor doodslag tot 12 jaar gevangenisstraf en tbs met dwangverpleging.

Het Hof Arnhem motiveert zijn beslissing als volgt:

'De wet noch de jurisprudentie vereist dat de stoornis wordt geclassificeerd volgens het handboek DSM-IV en dat deze dient te worden vastgesteld door een gedragsdeskundige. Dit betekent dat ... de

11 Zie voor vergelijkbare problematiek in een andere tbs-zaak A.R. Mackor en E. Brand, Naar een professioneler oordeel inzake TBS-verlengingen. Analyse van een casus. Proces 83 (2004) 4, pp. 167-174; A.R. Mackor en Ed Brand, Naschrift, Proces 84 (2005) 2, pp. 78-9; A.R. Mackor, TBS-verlenging zonder stoornis? NJB 80 (2005) 19, pp. 993-4 en C. de Ruiter, A.R. Mackor en R.J. van den Bosch, Rechter dwaalt door dubieuze rapportages over Marjan van der E, Volkskrant, 11 december 2007. 
rechter ... tot de vaststelling van een stoornis kan komen, ook al kunnen de gedragsdeskundigen op basis van de voor hen geldende wetenschappelijke criteria en tuchtrechtelijke normen niet tot die conclusie komen. Voor zijn beslissing dient de rechter dan wel voldoende steun te vinden in hetgeen gedragsdeskundigen zo mogelijk wél hebben kunnen vaststellen en hetgeen de rechter verder aan feiten en omstandigheden is gebleken met betrekking tot de persoon van verdachte. ...'

en

'Dit alles, in samenhang met de in deze strafmotivering weergegeven passages uit het strafdossier, maakt het voor het hof in voldoende mate aannemelijk dat bij verdachte tijdens het begaan van het feit een geestelijke stoornis of gebrekkige ontwikkeling van de geestvermogens bestond. Met de rechtbank is het hof van oordeel dat deze stoornis zodanig is dat het vanuit veiligheidsoogpunt onverantwoord is om verdachte onbehandeld terug te laten keren in de maatschappij.' (mijn cursiveringen ARM)

\section{Niet alleen de feiten, óók de theorie}

In beginsel kunnen we meegaan met het standpunt van het Hof dat de rechter niet, althans niet automatisch, is gebonden aan de Diagnostic and Statistical Manual of Mental Disorders (DSM-IV-TR), de meest recente versie van het psychiatrisch classificatiesysteem van psychische aandoeningen, of aan wetenschappelijke theorieën van gedragsdeskundigen. Mooij betoogt dat de rechter het psychiatrische classificatiesysteem niet hoeft aan te houden, omdat het in het recht gaat om de vraag of het vermogen tot redelijk overleg is aangetast. ${ }^{12}$ Dat mag zo zijn, maar dan rijst de vraag waarom precies de verplichting bestaat om gedragsdeskundigen in te schakelen. Waarin bestaat

12 A.W.M. Mooij, De vraag naar de toerekeningsvatbaarheid, Ontmoetingen, voordrachtenreeks van het Lutje Psychiatrisch-Juridisch Gezelschap, nr 11, 2005, pp 720, p 17. 
de gebondenheid van de rechter aan het oordeel van deskundigen? Waarin bestaat de autonomie om van dat oordeel af te wijken? Helaas zegt het Hof in de zaak van Julian C. hier niets over. Het stelt alleen dat de rechter voldoende steun moet vinden in wat gedragsdeskundigen wél hebben kunnen vaststellen, maar ook in wat de rechter verder aan feiten en omstandigheden is gebleken met betrekking tot de persoon van de verdachte. Het hof maakt niet duidelijk welk type gedragsdeskundige vaststellingen relevant zijn en maakt ook niet duidelijk aan de hand van welke criteria de rechter bepaalt welke overige 'feiten en omstandigheden' relevant zijn voor de vaststelling van de stoornis en, belangrijker nog, voor het vaststellen van het recidivegevaar.

Dit is uit juridisch perspectief misschien geen, maar uit wetenschappelijk perspectief wel een ernstig motiveringsgebrek. 'Feiten en omstandigheden' zijn immers niet 'freischwebend'; zij ontlenen hun betekenis aan een theorie. Toegespitst op het rechterlijke 'bewijs' ${ }^{13}$ van stoornis en recidiverisico: bewijsmiddelen zijn geen 'harde' feiten die voor zichzelf kunnen spreken, maar ontlenen hun betekenis als bewijs aan een theorie. Anders gezegd, als de rechter tot een 'bewezenverklaring' komt, dan zou hij niet alleen, zoals het Hof doet, moeten uitleggen op grond van welke feiten en omstandigheden, maar ook op grond van welke achterliggende theorie hij tot zijn conclusie is gekomen dat er sprake is van een stoornis én van recidivegevaar. Pas dan kunnen we beoordelen welke bewijskracht aan de opgesomde feiten en omstandigheden toekomt.

Een jurist zal hier wellicht tegenin willen brengen dat een rechter ook ten aanzien van de bewezenverklaring van het feit geen theorieën hoeft te hanteren, maar kan volstaan met een, meestal impliciete, verwijzing naar 'feiten van algemene bekendheid' (artikel 339 lid 2 Sv). Naar analogie zou kunnen worden geredeneerd dat de rechter daarmee ook kan volstaan bij de vaststelling van de stoornis en het recidiverisico. Het Hof geeft inderdaad, naast een uitgebreide samenvatting van verschillende gedragsdeskundige rapportages

13 Ik gebruik de termen bewijs en bewezenverklaring als het gaat over de vaststelling van het tenlastegelegde feit en de termen 'bewijs' en 'bewezenverklaring' als het gaat over de vaststelling van stoornis en recidiverisico. Zie daarover verder aan het eind van paragraaf 2. 
waaruit onmiskenbaar een 'zorgwekkend levensverhaal' naar voren komt, een zeer uitvoerige opsomming van feiten en omstandigheden die een leek de indruk geven dat verdachte een 'gevaarlijke gek' is. Het gaat hier onder meer om de 'feiten van algemene bekendheid' dat mensen die veel in zichzelf praten, die zich vreemd gedragen, die bizarre ideeën over energiestraling en zwaartekracht hebben, die midden in de nacht en op de raarste tijden hun familie opbellen en stemmingswisselingen hebben, lijden aan een psychische stoornis.

De vraag is echter welke rol deze common sense opvatting - dat het een feit van algemene bekendheid is dat mensen die dit soort gedrag vertonen een stoornis hebben en, belangrijker nog, gevaarlijk zijn - in het rechterlijk oordeel mag spelen. Nogmaals, wet noch jurisprudentie verbiedt de rechter om op basis van deze common sense opvatting tot het oordeel te komen dat verdachte een stoornis heeft en een gevaar voor de veiligheid vormt. Wel dringt zich de vraag op of de grondslag van het rechterlijke oordeel in het 'gezonde verstand' betrouwbaar genoeg is om tot een 'bewezenverklaring' van stoornis en recidiverisico te komen. Deze vraag klemt des te meer nu deskundigen aan al deze feiten en omstandigheden kennelijk geen of althans onvoldoende bewijskracht konden toekennen om tot een oordeel over stoornis en recidiverisico te komen. Deze vraag geldt vooral ten aanzien van de bepaling van het recidiverisico, omdat daar de normatieve component die, zoals Mooij terecht opmerkt, bij de bepaling van de stoornis nog wel een rol speelt, afwezig is.

\section{In dubio pro reo}

'In dubio pro reo' is een fundamenteel beginsel van het strafrecht. De vraag is of deze twijfel alleen moet prevaleren als het gaat om de bewezenverklaring van het strafbare feit, of evenzeer ten aanzien van de 'bewezenverklaring' van stoornis en recidiverisico.

Waarom oordeelt het Hof dat het zelf, zonder gedragsdeskundig advies, kan vaststellen dat er sprake is van een stoornis en van gevaar? Is de keuze van 
het Hof een bewijs van risico- of veiligheidsdenken: het opschuiven van het strafrechtelijk denken in termen van normen en normovertredingen naar een denken in termen van veiligheid en risico's? ${ }^{14}$ Of kan het ook, zoals Van Hattum lijkt te betogen, een keuze voor een humane bejegening zijn? ${ }^{15}$ Kan deze keuze worden gezien als laatste redmiddel om een weigerende verdachte tegen zichzelf te beschermen, namelijk door tbs op te leggen waar anders levenslange gevangenisstraf in het verschiet ligt? Van Hattum wijst in dit verband op het arrest van het Hof 's Hertogenbosch dat een stoornis niet bewezen achtte en Juliën C. tot een levenslange gevangenisstraf veroordeelde.

Als veiligheidsdenken en/of humanitaire overwegingen de achterliggende gedachten zijn, dan rijst de vraag of het strafrecht minder twijfelachtige veiligheids- en humanitaire kleppen heeft om de risico's te verkleinen en/of de verdachte menswaardig te bejegenen. Ik denk hier ten eerste aan de mogelijkheid om een verdachte naar een psychiatrisch ziekenhuis of tbskliniek over te laten plaatsen indien hij detentieongeschikt blijkt te zijn (artikel $13 \mathrm{Sr}$ ) en ten tweede aan de mogelijkheid van een rechterlijke machtiging indien blijkt dat verdachte na het uitzitten van zijn straf een gevaar is voor zichzelf of anderen. Ten slotte, bij levenslange gevangenisstraf kán gratie worden verleend. Van Hattum heeft echter gelijk dat de tbs op dit punt met meer waarborgen is omkleed dan de levenslange gevangenisstraf, omdat de verlenging met de tbs regelmatig ambtshalve door de rechter wordt getoetst.

Strafrecht is tegelijk instrument in handen van de overheid om veiligheid te waarborgen én waarborg in handen van de burger tegenover diezelfde overheid. Voor beide doelen werd strafrecht in het leven geroepen. Het recht van de overheid onderscheidt zich van veel andere regelsystemen omdat het -

14 A.R. Mackor, Strafrecht en liberalisme. Ontwikkelingen rond strafrecht waarover liberalen zich zorgen zouden moeten maken, te verschijnen in Rechtsfilosofie \& Rechtstheorie 41 (2012) 1.

15 W.F. van Hattum, Tbs of levenslang; de marge van de strafrechter en de rol van de deskundige. Een beschouwing naar aanleiding van de strafzaak tegen Julien C., in F. Koenraadt en I. Weijers (red.), Vrijheid en verlangen. Liber amicorum prof.dr. Antoine Mooij, Den Haag: Boom Juridische Uitgevers, 2009, pp 125-149. 
nadat het in de politieke arena meestal voor meerdere soms conflicterende en vaak niet scherp omschreven doelen gecreëerd is - áls recht vervolgens grotendeels autonoom is ten opzichte van diezelfde politieke doelen. Dat is een fundamentele betekenis van de rechtsstaat. Daarmee verschillen (de meeste) rechtsregels, en bij uitstek die van het strafrecht, fundamenteel van 'doelnormen', zoals recepten in een kookboek, omdat zij niet naar willekeur mogen worden gevormd en vervormd met het oog op één of meer van de achterliggende doelen. Wie een luchtige cake wil bakken, maar niet het voorgeschreven aantal eieren in huis heeft, mag het recept aanpassen aan het aantal eieren dat hij wel tot zijn beschikking heeft. De rechter daarentegen moet de wet toepassen, ook als de uitkomst hemzelf of doeldenkers onwelgevallig is. ${ }^{16}$ Alleen zo biedt het recht rechtszekerheid en rechtsgelijkheid. Het is niet aan de rechter, maar aan de politiek om de wet aan te passen. In het geval van oplegging van tbs bij weigerende verdachten is dat gebeurd via de reeds genoemde Reparatiewet. In deze bijdrage heb ik betoogd dat deze aanpassing, net als de uitleg van het Hof Arnhem in de Hoogerheide zaak, op gespannen voet staat met vereisten van betrouwbare strafrechtelijke bewijsvinding.

Men zou misschien kunnen betogen dat de opvatting dat een rechter het zwijgen van een verdachte in zijn nadeel mag laten wegen ${ }^{17}$ ook van toepassing is op een verdachte die weigert aan onderzoek mee te werken. Niet omdat niet meewerken op zichzelf als een aanwijzing voor een stoornis kan worden gezien; dat lijkt mij een standpunt dat alleen psychiaters in de voor-

16 A.R. Mackor, TBS en techniek, Over het gebruik van risicotaxatie-instrumenten in Pro Justitia rapporten, in het themanummer 'Nemen de apparaten het over?', Tijdschrift voor Humanistiek, $\mathrm{nr} 23,6^{\mathrm{e}} \mathrm{jrg}$. oktober 2005, pp. 6-15.

17 Zie Knigge 2010, p 183; EHRM 8 februari 1996, 18731/91 (John Murray vs. UK) en Hoge Raad 3 juni 1997, NJ 1997, 584 (Strippenkaart). In laatstgenoemd arrest overweegt de Hoge Raad: "De omstandigheid dat een verdachte weigert een verklaring af te leggen of een bepaalde vraag te beantwoorden kan op zichzelf, mede gelet op het bepaalde in art. 29, eerste lid, Sv, niet tot het bewijs bijdragen. Dat brengt echter niet mee dat de rechter, indien een verdachte voor een omstandigheid, die op zichzelf of in samenhang met de verdere inhoud van de bewijsmiddelen beschouwd redengevend moet worden geacht voor het bewijs van het aan hem telastegelegde feit, geen redelijke, die redengevendheid ontzenuwende, verklaring heeft gegeven, zulks niet in zijn overwegingen omtrent het gebezigde bewijsmateriaal zou mogen betrekken." 
malige Sovjet-Unie voor hun rekening zouden willen nemen. Misschien zou wel naar analogie geredeneerd kunnen worden dat een weigerende verdachte een eventueel onjuist oordeel over stoornis en gevaar aan zichzelf te wijten heeft. Dat is een interessante gedachte, maar ik heb er grote twijfels bij. Hij lijkt immers te impliceren dat een verdachte tot op zekere hoogte verplicht is mee te werken aan zijn veroordeling, hetzij tot straf, hetzij tot tbs.

Mijn conclusie luidt daarom: ook al staat het Nederlandse strafrecht het toe, een autonoom strafrechter zou het standpunt moeten innemen dat hij niet op eigen houtje, dat wil zeggen zonder ten minste twee gedragsdeskundige adviezen, tot het oordeel kan komen dat er sprake is van een stoornis en van recidiverisico. ${ }^{18}$

18 Ik bedank alle aanwezigen bij de bijeenkomst van het Lutje Psychiatrisch Juridisch Gezelschap op 15 september 2011, in het bijzonder Wiene van Hattum, voor hun inspirerende inbreng in de discussie. Ook bedank ik Diederik Aben voor zijn grondige commentaar op een eerdere versie van dit artikel. Deze reacties hebben tot uitwerking en aanpassing van mijn betoog geleid. 